\title{
Urothelial carcinoma of the bladder in Swedish geriatric patients: a population-based study
}

\begin{abstract}
Background: The aim of this study was to describe age at presentation, treatment and cancer-specific survival in patients with urinary bladder cancer (UBC) in a populationbased cohort, with special reference to patients 75 years or older.

Methods: All primary UBC patients with urothelial pathology reported to the Swedish National Registry of Urinary Bladder Cancer (SNRUBC) from 1997 to 2014 were included in the study. Groups were compared regarding age at diagnosis, primary treatment and survival.

Results: A substantial proportion of the patients were diagnosed with UBC late in life; $10.7 \%$ of the men and $15.0 \%$ of the women were aged $>85$ ys at presentation. In the group of patients with T1 UBC, the patients aged 75ys or older were less often treated with intravesical installation therapy $(\mathrm{p}<0.001)$. The patients aged $75 \mathrm{ys}$ or older with T1 UBC had an inferior cancer-specific survival $(\mathrm{p}<0.001)$ compared to younger patients.
\end{abstract}

Conclusion: In this population-based cohort comprising virtually all patients diagnosed with UBC in Sweden, age 75 ys or older is associated with an inferior proportion of patients who undergo intravesical instillation therapy. Age 75 ys or older is also associated with an inferior cancer-specific survival in urinary bladder cancer.
Volume I Issue 3 - 2017

\author{
Carin Sjöström,' Andreas Thorstenson, ${ }^{2}$ \\ Staffan Jahnson ${ }^{3}$ \\ 'Department of Molecular Medicine and Surgery, Section of \\ Urology, Karolinska Institute, Sweden \\ ${ }^{2}$ Department of Surgery, Section of Urology, Capio S:t Görans \\ Hospital, Sweden \\ ${ }^{3}$ Department of Urology, University Hospital, Linköping \\ University, Sweden
}

\begin{abstract}
Correspondence: Andreas Thorstenson, Capio S:t Görans Hospital, Department of Surgery, Sweden, Tel +46-70-0017195, Fax +46-8-58703304,
\end{abstract}

Email andreas.thorstenson@capiostgoran.se

Received: March 30, 2017| Published: May 16, 2017

Keywords: bladder cancer, geriatric, population-based, survival

\section{Introduction}

Urinary bladder cancer (UBC) is a common disease in an aged population. ${ }^{1}$ UBC is known to have an inferior survival among the elderly compared to younger patients.,3 There has been publications suggesting an inferior effect on intravesical instillation therapy in octogenarians. ${ }^{4}$ Our aim was to use a population-based cohort to further explore age at presentation, primary treatment, and survival in geriatric patients with UBC in Sweden.

\section{Materials and methods}

In Sweden, all patients with newly diagnosed UBC are reported to a regional UBC registry. The regional registries are cross-linked with the Swedish Cancer Registry (SCR), and thereby missing patients can be identified. Data from the regional registers are validated and checked by the respective regional cancer centres and reported continuously online to the national registry. The Swedish National Registry of Urinary Bladder Cancer (SNRUBC) was started in 1997 and has a coverage rate of more than $95 \%$ compared to the SCR. It has been mandatory to report all newly detected cancer patients in the country to the SCR since 1958, and the reporting is done by both clinicians and pathologists independently to ensure a 100\% coverage of all diagnosed malignant tumors.

The SNRUBC represents a compilation of clinical data on virtually all patients newly diagnosed with UBC in Sweden, including information on histopathological tumor type, tumor grade, TNM classification, and primary treatment and has been described in a previous publication. ${ }^{5}$ Information regarding time and cause of death was acquired from the Swedish Cause of Death Registry.

\section{Statistical analysis}

Descriptive statistics are given in the table. Statistical tests, including chi square or t-tests when appropriate, were calculated using two-tailed tests. A two-tailed $p$-value $<0.05$ was considered statistically significant. Cancer-specific survival was computed by the Kaplan-Meier method, and groups were compared using the Log-rank test with $\mathrm{p}<0.05$ considered statistically significant. All statistical analyses were performed using SPSS version 24.0 (IBM Corp, Michigan, USA).

\section{Results}

\section{Patients and tumor characteristics}

Between 1997 and 2011, 31283 patients were diagnosed with UBC in Sweden and reported to the SNRUBC. After exclusion of 973 patients with histopathology other than UBC, 30310 patients in all stages remained for analysis: 22690 men $(74.9 \%)$ and 7620 women $(25.1 \%$, Table 1$)$. In this population-based cohort the men were younger at the time of diagnosis. The median age at presentation was 73 ys (interquartile range [IQR] 65-80ys) for men and 74ys (IQR 65$81 \mathrm{ys})$ for women $(\mathrm{p}<0.001)$. A substantial proportion of the patients were diagnosed with all stage UBC late in life; $10.7 \%$ of the men and $15.0 \%$ of the women were aged $>85 \mathrm{ys}$ at presentation. The tumor characteristics of the cohort are presented in (Table 1).

Table I Tumor characteristics of 30310 patients diagnosed with urinary bladder cancer in Sweden 1997 to 201 I

\begin{tabular}{ll} 
Male Patients & $22690(74.9 \%)$ \\
Female Patients & $7620(25.1 \%)$ \\
\hline
\end{tabular}


Table Continued....

$\begin{array}{lll}\text { Tumor Stage } & \text { Ta } & \text { I } 4428(48 \%) \\ & \text { CIS* } & 828(2.7 \%) \\ & \text { TI } & 6730(22 \%) \\ \text { T2 } & 4920(16 \%) \\ & \text { T3 } & 1683(5.6 \%) \\ \text { Tumor Grade } & \text { PUNLMP* } & \text { I0I4 (3.4\%) } \\ & \text { GI } & 740(1.8 \%) \\ & \text { G2 } & 9943(33 \%) \\ & \text { G3 } & \text { II } 689(39 \%) \\ & \text { GX } & 404(1.4 \%)\end{array}$

\section{*Carcinoma in situ}

${ }^{\times}$Papillary urinary neoplasm of low malignant potential

We further selected all the Swedish patients diagnosed with UBC stage T1 between 1997 and 2014 (Table 2). Patients with metastatic disease and patients who underwent radical cystectomy or radiotherapy with curative intention were excluded from the analysis.
In this cohort of 7661 patients the median age at presentation with T1 UBC was 74ys (IQR 67-81ys). Similar to the cohort above, the women presented with $\mathrm{T} 1 \mathrm{UBC}$ at a more advanced age compared to men.

We could identify a diagnostic shift in patients $75 \mathrm{ys}$ or older. For the patients 75 ys or older it was more common to be diagnosed with a non-muscle-invasive UBC during the later period of the study 2006-2014, compared to the earlier period of the study 1997-2005 $(\mathrm{p}<0.001)$

\section{Treatment and cancer-specific survival}

In the group of patients with $\mathrm{T} 1 \mathrm{UBC}$, the patients aged 75 or older were less often treated with intravesical installation therapy $(\mathrm{p}=0.001)$, however the frequency of re-resections (second TURB) did not differ between older and younger patients $(\mathrm{p}=0.87)$.

The patients aged 75ys or older with T1 UBC had an inferior cancer-specific survival compared to younger patients $(p=0.001)$. The risk of death in UBC for patients 75ys or older was HR 2.51 (95\% CI 2.24-2.82). Age and tumor grade were the only statistically significant factors influencing the risk of cancer-specific mortality besides the access to/ability to undergo state-of-the-art treatment.

Table 2 Characteristics of patients diagnosed with urinary bladder cancer stage TI in Sweden 1997 to 2014 stratified for age

\begin{tabular}{|c|c|c|c|c|}
\hline & $\begin{array}{l}\text { No. of patients } \\
<75 \text { Ys (\%) }\end{array}$ & $\begin{array}{l}\text { No. of patients } \\
\geq 75 \text { Ys (\%) }\end{array}$ & $\begin{array}{l}\text { No. of patients } \\
\text { All Ages (\%) }\end{array}$ & P-value \\
\hline All patients & $3833(50)$ & $3828(50)$ & $766 I(100)$ & n.a. \\
\hline Male & 3031 (79) & $2895(75)$ & $5926(77)$ & n.a. \\
\hline Female & $810(21)$ & $945(25)$ & $1755(23)$ & n.a. \\
\hline Intravesical instillation therapy & $1769(46)$ & $1079(28)$ & $2848(74)$ & $<0.001$ \\
\hline Re-resection (second TURB) & $966(25)$ & $74 \mid(19)$ & I707 (44) & 0.87 \\
\hline Cancer-specific survival & 3151 (88) & $2783(78)$ & $5934(77)$ & $<0.001$ \\
\hline
\end{tabular}

\section{Discussion}

Urinary bladder cancer is a common disease in a geriatric population. Women present with the disease somewhat later in life compared to men. In a review of the influence of age and gender on UBC, Shariat et al. ${ }^{6}$ showed that, compared to men, women present with a more advanced disease and have worse survival rates, differential exposure to carcinogens, and disparate referral patterns, and are also affected by different genetic, anatomical, hormonal, social, and environmental factors. ${ }^{6}$ In the present cohort, the median age at the time of diagnosis of UBC was one year older in women than in men. This observation confirms the findings of a study in Spain with patients diagnosed with UBC between 1997 and 2000, in which women were significantly older than the men at presentation. ${ }^{7}$ In another study assessing a cohort of 1168 patients diagnosed with UBC in England between 2005 and 2011, the median age at presentation was 75 years for women and 73 years for men. ${ }^{8}$ A Swedish report has shown age-related differences in the treatment of muscle-invasive bladder cancer, ${ }^{9}$ and it would be unsurprising if similar mechanisms could explain some of the age-related differences in patients with T1 UBC. On the other hand it can be argued that the expected lifespan for men and women normally differs with 3 to 4 years in favour of women, which would make the under treatment of women even more profound.
In the group of patients with $\mathrm{T} 1 \mathrm{UBC}$, the patients aged 75ys or older were less often treated with intravesical installation therapy. Unfortunately, this observation confirms previous data showing that more intensive intravesical therapy is given to men and younger patients in Sweden. ${ }^{5,10}$ The reasons behind the under treatment of octogenarians are not fully understood and is subject to on-going work by our group. There is probably a proportion of the octogenarians with T1 UBC who have to much co-morbidity to undergo intravesical instillation of bacillus Calmette-Guérin (BCG). Data on co-morbidity is unfourtunately not available in this cohort at present. Aging progressively weakens the immune system due to a decline in the adaptive immune response. High age is also a risk factor for side effects from BCG suck as fever, urgency and hematuria. ${ }^{11}$

We identified a diagnostic shift in patients $75 y$ s or older. In the later period of the study, 2006 to 2014, significantly more octogenarians were diagnosed with UBC. This may represent a trend in society towards a more active medical management of octogenarians in general. It can also be a result of the increased use of computed tomography $(\mathrm{CT})$. Supporting the trend of a more active management of octogenarians is also the fact that we could not show a difference in the proportion of younger vs older patients who underwent reresection. 
The patients with T1 UBC 75ys or older had an inferior cancerspecific survival compared to the younger patients. It is natural to suggest an association with the under treatment of BCG in patients $75 \mathrm{ys}$ or older. However, BCG has never been shown to increase the cancer-specific survival in UBC only to decrease recurrence and progression. ${ }^{12}$ It has long been known that patients who present with UBC at a more advancerd age has a worse prognosis compared to younger patients. The mechanisms behind this are not fully understood.

Several population-based UBC cohorts have been described in the literature, ${ }^{13,14}$ but none of them has been larger than the present cohort. The data set we used was collected in a prospective fashion and represented virtually all patients with newly diagnosed UBC in the Swedish population. The data reported to the SNRUBC are continuously validated at the treatment centres, which reduces the likelihood of aberrant information. Therefore, selection bias is unlikely, and the study population can be considered as fully representative of UBC patients in Sweden. A limitation of our study is that clinical, radiological, and histopathological data were gathered from all the Swedish hospitals, which may have entailed discrepancies in interpretations.

In conclusion we find that Swedish patients with urinary bladder cancer aged $75 \mathrm{ys}$ or older undergo intravesical instillation therapy less frequently compared to younger patients. Age 75ys or older is also associated with an inferior cancer-specific survival in UBC.

\section{Appendix}

Oskar Hagberg, Sten Holmäng, Abolfazl Hosseini, Truls Gårdmark, Staffan Jahnson, Fredrik Liedberg, Börje Ljungberg, and Per-Uno Malmström are members of the National Swedish Registry of Urinary Bladder Cancer.

\section{Acknowledgements}

None.

\section{Conflict of interest}

Author declares there is no conflict of interest in publishing the article.

\section{References}

1. Jensen TK, Jensen NV, Jørgensen SM, et al. Trends in cancer of the urinary bladder and urinary tract in elderly in Denmark, 2008-2012. Acta Oncol. 2016;55(1):85-90.
2. Chamie K, Mark SL, Jeffrey CB, et al. Recurrence of high-risk bladder cancer: a population-based analysis. Cancer. 2013;119(17):3219-3227.

3. Noon AP, Albertsen PC, Thomas F, et al. Competing mortality in patients diagnosed with bladder cancer: evidence of undertreatment in the elderly and female patients. Br J Cancer. 2013;108(7):1534-1540.

4. Oddens JR, Sylvester RJ, Brausi MA, et al. The effect of age on the efficacy of maintenance bacillus Calmette-Guerin relative to maintenance epirubicin in patients with stage Ta T1 urothelial bladder cancer: results from EORTC genito-urinary group study 30911. Eur Urol. 2014;66(4):694-701.

5. Thorstenson A, Hagberg O, Ljungberg B, et al. Gender-related differences in urothelial carcinoma of the bladder: a population-based study from the Swedish National Registry of Urinary Bladder Cancer. Scand J Urol. 2016;50(4):292-297.

6. Shariat SF, Sfakianos JP, Droller MJ, et al. The effect of age and gender on bladder cancer: a critical review of the literature. BJU Int. 2010;105(3):300-308.

7. Puente D, Malats N, Cecchini L, et al. Gender-related differences in clinical and pathological characteristics and therapy of bladder cancer. Eur Urol. 2003;43(1):53-62.

8. Bryan RT, Zeegers MP, van Roekel EH, et al. A comparison of patient and tumour characteristics in two UK bladder cancer cohorts separated by 20 years. BJU Int. 2013;112(2):169-175.

9. Jahnson S, Damm O, Hellsten S, et al. A population-based study of patterns of care for muscle-invasive bladder cancer in Sweden. Scand J Urol Nephrol. 2009;43(4):271-276.

10. Gardmark T, Anna Bladström. Analysis of clinical characteristics, management and survival of patients with Ta T1 bladder tumours in Sweden between 1997 and 2001. Scand J Urol Nephro. 2006;140(4):276-282.

11. Francesco S, Marco M, Stephan K, et al. How to optimally manage elderly bladder cancer patients? Transl Androl Urol. 2016;5(5):683-691.

12. Chou R, Shelley S, David IB, et al. Intravesical Therapy for the Treatment of Nonmuscle Invasive Bladder Cancer: A Systematic Review and MetaAnalysis. J Urol. 2017;197(5):1189-1199.

13. Larsson P, Wijkström H, Thorstenson A, et al. A population-based study of 538 patients with newly detected urinary bladder neoplasms followed during 5 years. Scand J Urol Nephrol. 2003;37(3):195-201.

14. Puente D, Malats N, Cecchini L, et al. Gender-related differences in clinical and pathological characteristics and therapy of bladder cancer. Eur Urol. 2003;43(1):53-62. 